\title{
LETTERS
}

3. Müller M P Hänsel M, Stehr S N, Weber S, Koch T. A state-wide survey of medical emergency management in dental practices: incidence of emergencies and training experience. Emerg Med $J$ 2008; 25: 296-300

DOI: 10.1038/sj.bdj.2012.271

\section{BLOW AWAY THE INERTIA}

Sir, in the early 1980 s as a dental undergraduate I was taught the huge benefits of water fluoridation. It was, and remains a central plank of teaching on the prevention of dental caries. So why after nearly 30 years has nothing really happened?

As a practitioner working in a city centre practice for almost 30 years I understand the benefits of establishing a preventive philosophy in my practice. I see the results daily of a long campaign on diet and oral hygiene in terms of reduced caries rates and healthier dentitions. I am fully aware though that all of this work would be massively supported and massively dwarfed in impact by the introduction of fluoridation in my area. So why are we still waiting?

Late last year I decided that the time was right to try and blow away the inertia surrounding fluoridation and try to raise the profile of this public dental health measure. The e-petition can be accessed at: http://epetitions.direct.gov. uk/petitions/18219 (Fig. 1).

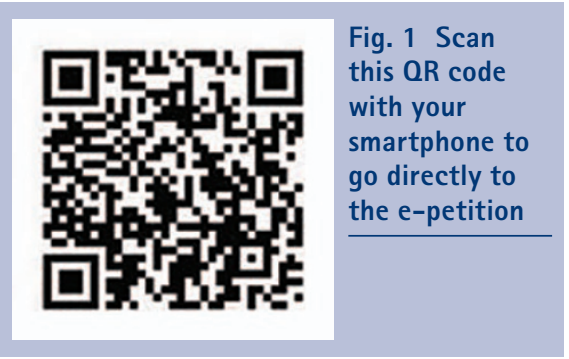

The strategy is to gain some serious momentum for fluoridation amongst the dental profession and then to begin looking at how we can engage patients and local stakeholders in order that when a local consultative process on fluoridation is commenced in our individual areas we have a strong local support that can lobby effectively. For too long fluoridation has been derailed by poor communication, misleading information and myth.

The purpose of the petition is simply to demonstrate support. Debates on targeted use can begin later. Let's face it, if the profession cannot endorse fluoridation - how can we expect the public to support it? This is an opportunity to break out of this state of mind and finally work towards establishing fluoridation nationwide. Are we up to the challenge? I hope so. We owe it to future generations to move this forward. If not, why waste time teaching it?

S. Hearnshaw

Chairman Hull and

East Riding Of Yorkshire LDC DOI: 10.1038/sj.bdj.2012.272

\section{UNRECOGNISABLE WORLD}

Sir, in over 40 years as a dentist I have never felt the urge to respond to a letter from a colleague printed in the $B D J$. That is until reading the letter by P. Mc Crory (BDJ 2012; 212: 103) on antibiotic prescribing in primary care.

Dr Mc Crory suggests that before dentists in a primary care setting prescribe antibiotics to a patient they should first telephone an appointed service specialist to discuss the case and, if both clinicians agree, a code to validate the signature on the prescription would be issued by the support service. If mutual agreement could not be reached then a third clinician's opinion would be sought. All this to take place when one is confronted with a patient with pericoronitis who has been fitted in between a ten o'clock extraction and a ten fifteen filling appointment.

Of course if this were to apply to GDPs, it would have to apply to GPs as well or dentists would be seen as being insufficiently qualified to prescribe without prior permission.

I don't know what world Dr Mc Crory lives in but it's not one I recognise.

\section{Wilson, Esher}

DOI: 10.1038/sj.bdj.2012.273

\section{INTERPRETATION CONSIDERATION}

Sir, I write in response to the paper by S. Critchlow and L. Nanayakkara, $A$ guide to entry into specialist training (BDJ 2012: 212: 35-40).

Being a recent graduate currently going through an era of endless application forms, this paper plays particular relevance to myself. Firstly, I would like to acknowledge the authors for the invaluable information provided within this paper, after all every little helps from those that have been through this challenging process. However, I have noted a mistake. The Diploma of Membership of the Faculty Dental Surgery (MFDS) offered by the Royal College of Surgeons of Edinburgh can in fact be awarded after 12 months of postgraduate clinical dental experience, not 24 months. These regulations were adjusted in September 2010. ${ }^{1}$ Evidence of 12 months' clinical dentistry experience is a requirement for the MFDS part 2 examinations, meaning that if one passes this exam, they can then at that time be elected and awarded the diploma, and do not require two years' clinical experience.

Furthermore, I would like to question how 'desirable' it is to actually have a prize? The selection panel should be mindful that some dental schools give out prizes like free pens at trade fairs. A prize at school A may be significantly harder to achieve than at school B, so the interpretation of having a prize must be taken with careful consideration.

A. Maqbool

By email

1. The Royal College of Surgeons of Edinburgh. Dental Surgery Examination Regulations. http://www. rcsed.ac.uk/site/698/default.aspx

DOI: 10.1038/sj.bdj.2012.274

\section{URGENT ATTENTION AND TREATMENT}

Sir, a long-standing patient of our practice, a 77-year-old Afro-Caribbean male who suffered from type II diabetes and hypertension, was undergoing a composite filling, when a slow but progressive swelling started developing around the lips, tongue and buccal mucosa (Fig. 1).

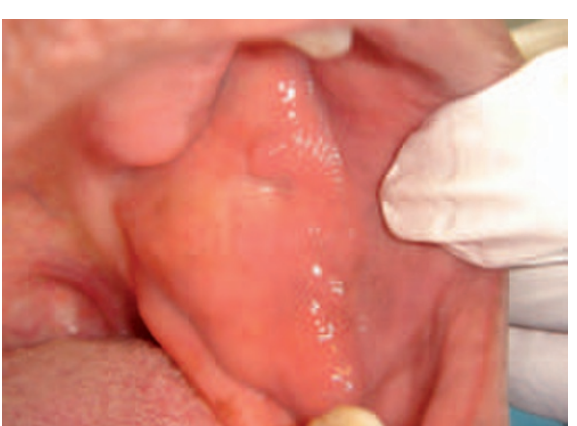

Fig. 1 Swelling developing around the lips, tongue and buccal mucosa 